\title{
Targeting cancer stem cells: emerging role of Nanog transcription factor
}

This article was published in the following Dove Press journal:

OncoTargets and Therapy

5 September 2013

Number of times this article has been viewed

\author{
Mong-Lien Wang' \\ Shih-Hwa Chiou ${ }^{2,3}$ \\ Cheng-Wen Wu ${ }^{1,4-6}$ \\ 'Institute of Biochemistry and \\ Molecular Biology, ${ }^{2}$ Institute \\ of Pharmacology, National Yang \\ Ming University, Taipei, Taiwan; \\ ${ }^{3}$ Department of Medical Research \\ and Education, Taipei Veterans \\ General Hospital, Taipei, Taiwan; \\ ${ }^{4}$ Institute of Microbiology and \\ Immunology, Institute of Clinical \\ Medicine, National Yang Ming \\ University, Taipei, Taiwan; ${ }^{6}$ Institute \\ of Biomedical Science, Academia \\ Sinica, Taipei, Taiwan
}

\begin{abstract}
The involvement of stemness factors in cancer initiation and progression has drawn much attention recently, especially after the finding that introducing four stemness factors in somatic cells is able to reprogram the cells back to an embryonic stem cell-like state. Following accumulating data revealing abnormal elevated expression levels of key stemness factors, like Nanog, Oct4, and Sox2, in several types of cancer stem cells; the importance and therapeutic potential of targeting these stemness regulators in cancers has turned to research focus. Nanog determines cell fate in both embryonic and cancer stem cells; activating Nanog at an inappropriate time would result in cancer stem cells rather than normal pluripotent stem cells or differentiated somatic cells. Upregulated Nanog is correlated with poor survival outcome of patients with various types of cancer. The discoveries of downstream regulatory pathways directly or indirectly mediated by Nanog indicate that Nanog regulates several aspects of cancer development such as tumor cell proliferation, self-renewal, motility, epithelial-mesenchymal transition, immune evasion, and drug-resistance, which are all defined features for cancer stem cells. The current review paper illustrates the central role of Nanog in the regulatory networks of cancer malignant development and stemness acquirement, as well as in the communication between cancer cells and the surrounding stroma. Though a more defined model is needed to test the therapeutic efficacy of targeting Nanog as a cancer treatment method, current animal experiments using siNanog or shNanog have shown the promising therapeutic potential of Nanog targeting in several types of cancer.
\end{abstract}

Keywords: cancer stemness, target therapy

\section{Cancer stem cells}

Human tissues, under physiological conditions, are able to maintain their mass and architecture over time through a tightly regulated process of renovation. This process is sustained by a minor population of long-lived cells with unlimited expansion potential, known as stem cells, which are defined as cells that have the ability to perpetuate themselves through self-renewal and to generate mature cells of a particular tissue through differentiation.

Tumors can be considered as aberrant organs that are initiated by tumorigenic cancer cells that acquired the capacity for indefinite proliferation through accumulating mutations. Like their normal tissue counterparts, tumors are composed of heterogeneous populations of cells that differ in their degree of accumulated mutations and state of differentiation. Evidence was outlined in supporting the hierarchical organization of normal human breast tissue and the breast stem or luminal progenitor cells as targets for transformation. ${ }^{1}$ The idea that cancer is raised from a subpopulation
Correspondence: Cheng-Wen Wu Institute of Biochemistry and Molecular Biology, National Yang Ming University, No I55, Sec 2, Li-Nong St, Peitou,

Taipei II2, Taiwan

Tel +886228267919

Fax +886228236518

Email cwwu@ym.edu.tw 
of tumor cells with stem cell properties, which are latterly termed cancer stem cells (CSCs), was proposed around 150 years ago. ${ }^{1,2}$ This unique subpopulation of cancer cells are capable of propagating the tumor as well as developing high sustainability against conventional therapeutic drugs, and, therefore, account for intratumoral heterogeneity and malignant behaviors like metastasis and recurrence. ${ }^{2}$ Though the identity of CSCs is still argued, the definition of CSCs is in concord based on the functional characteristics of these cells: the ability to initiate tumors in immunocompromised or syngeneic mice, self-renewal capacity measured by tumor formation in secondary mice in vivo and sphere formation in vitro, and the capacity to differentiate into the non-selfrenewable cancer cells with diversity. ${ }^{1}$

\section{Identification of CSCs}

During the last decades, the existence and the identity of CSCs have been identified in hematopoietic tumors as well as a range of solid tumors including breast, brain, lung, colon, prostate, head and neck, and others. ${ }^{3-11}$ This rare subpopulation of cells with chemo- or radioresistant properties in each malignancy has greater potential of tumor initiation and accelerated regrowth after a therapeutic treatment. ${ }^{9,11-20}$ Breast cancer was the first solid tumor from which CSC was isolated: the breast CSC was characterized as a minor population (less than 5\%) of cells expressing a high level of CD44 and a low level of CD24 cell surface markers as well as being positive for epithelial cell surface antigen. ${ }^{13,21}$ As few as 100 of the cells with this phenotype were able to form tumors in immunocompromised mice. ${ }^{13}$ Technically, CSCs can be isolated through three distinct methodologies based on the defined properties of CSCs. First of all, CSCs can be sorted by flow cytometry according to the expression pattern of surface markers such as CD24, CD44, and CD133. 4,7,22-24 For example, colon, lung, and hematopoietic CSCs are isolated by cell sorting with the expression of CD133, 7,8,22,25,26 though the function of CD133 is still unclear. These cells grow indefinitely as spheres in vitro and were tumorigenic in vivo. ${ }^{8}$ Second, with Hoechst 33342 staining, CSCs are enriched in the side populations of cancer cells, excluding intracellular Hoechst 33342 in vitro, ${ }^{27,28}$ and can be isolated by flow cytometry. Expression of ATP-binding cassette subfamily G member 2 (ABCG2), an ATPase transporter, in CSC is found closely associated with its specific exclusion capacity, rendering ABCG2 a CSC marker in some cases. ${ }^{29}$ Third, CSCs are enriched in a population of cells that are capable of forming sphere bodies under defined serum-free cultivation medium plus necessary growth factors according to individual solid tumor or cancer. ${ }^{14,30}$ This cultivation condition also helps the CSC to maintain its undifferentiated state. ${ }^{14,30}$

\section{CSCs as therapeutic target}

The increasing interests in the CSC model are dramatically altering the current research directions in cancer treatments and drug developments. The majority of cancer cells within a tumor are nontumorigenic; therapies targeting these cells would cause tumor regression. However, if therapies fail to target the tumorigenic CSCs, then these cells would persist after therapies and be able to regenerate the tumor, resulting in tumor relapse or recurrence. Therefore, eradication of cancers requires the elimination of CSCs. Advanced strategies that specifically target CSCs without harming normal cells are urgently needed to advance current therapeutic treatments. The origin of CSCs is still debated as they may be derived from adult stem cells, which accumulate oncogenic mutations to functionally divert from normal stem cells, or from terminally differentiated cancer cells that undergo a reprogramming-like process to acquire stem-like properties. It is, however, generally accepted that several embryonic stem cell-specific signalings are reactivated in CSCs in several cancer models. The embryonic stem cell-specific transcriptional factor, Nanog, for instance, was shown to highly express in hepatic, colorectal, and brain CSCs. ${ }^{31-33} \mathrm{CSCs}$ in brain tumors were demonstrated to express various neural stem/ progenitor-specific proteins such as sex determine region Y-box 2 (Sox2), octamer-binding transcription factor 4 (Oct4 [also known as POU5F1]), nestin, and Musashi. ${ }^{15}$ Our previous report demonstrated high expression of Oct4 and Nanog in malignant lung adenocarcinoma cells, and forced overexpression of Oct 4 and Nanog transformed the lung cancer cells into a CSC-like state. ${ }^{34}$ Accumulating reports have recently placed interests on identifying CSC molecules, including transcription factors, cell surface markers, stemness-related signaling pathways, and microRNAs (miRNAs), in the hope of identifying targets for potential therapeutic development that can completely eliminate CSCs and prevent the recurrence of tumors.

\section{The Nanog transcriptional factor}

Nanog is a homeodomain-containing transcription factor and, along with the POU domain-containing Oct4 and high mobility group domain-containing Sox2, is part of the key set of transcription factors that are involved in the maintenance of pluripotency and selfrenewal in undifferentiated embryonic stem (ES) cells. ${ }^{35-41}$ Nanog protein is encoded by the only open reading frame of the 2184 -nucleotide $N A N O G$ cDNA. ${ }^{35}$ 
Apart from the embryonic $N A N O G$ gene, there are eleven Nanog pseudogenes that have been reported in the human genome to date, ${ }^{42}$ but only the Nanog homeobox pseudogene 8 (NANOGP8) has a complete open reading frame to transcribe and translate a functional Nanog protein. ${ }^{42-44}$ The protein derived from NANOGPS is almost identical to that from $N A N O G$ with only one amino acid alteration (from Gln253 in NANOG to His-253 in NANOGP8). ${ }^{5}$ Comprehensive expression patterns of $N A N O G$ and NANOGP8 in human cancers have not been fully addressed. Although it is presumed that embryonic $N A N O G$ is an important regulator of pluripotency while NANOGP8 plays a role in tumorigenesis, ${ }^{5}$ the defined line between the roles of the two genes is becoming blurred. A functional and molecular analysis in prostate cancer tissue revealed that Nanog mRNA in cancer cells is derived predominantly from $N A N O G P 8$, and the majority of Nanog protein is detected in the nucleus of cancer cells. ${ }^{45} \mathrm{On}$ the other hand, Nanog was found to be expressed from both NANOG and NANOGP8 in colorectal cancers. ${ }^{5}$

Human Nanog protein consists of 305 amino acids ${ }^{35,36}$ and can be divided into N-terminal (amino acid 1-95), homeobox domain (amino acid 96-155), and C-terminal (amino acid 156-305) regions. ${ }^{35,46}$ The N-terminus is rich in serine, threonine, and proline, providing a structural motif for the transcriptional activity of Nanog. This region is tightly regulated through phosphorylation or other posttranslational modifications. ${ }^{46,47}$ The $\mathrm{C}$-terminus contains two potent transactivation subdomains. ${ }^{46,47}$ The homeobox domain in the central region contains a DNA-binding motif; its $\mathrm{N}$ - and $\mathrm{C}$-terminal regions are shown to contain nuclear localization sequences ${ }^{47}$ and its middle region is reported to harbor potent nuclear export motif, ${ }^{48}$ allowing the Nanog protein to transport in and out of the nucleus. Nanog is also one of the key transcription factors that could reprogram a human somatic fibroblast into an embryonic stem cell-like pluripotent cell, termed inducible pluripotent stem cell. ${ }^{49}$ A recent study revealed that a short sequence in the well conserved homeobox domain of Nanog was sufficient to induce pluripotency in Nanog-deficient somatic cells, ${ }^{50}$ indicating a crucial role of the homeobox domain in mediating the reprogramming ability of Nanog and that the transcriptional activity of Nanog might be dispensable.

\section{Roles of Nanog in embryonic stem cells}

Nanog mRNA is present in pluripotent mouse and human stem cell lines, and absent from differentiated cells. ${ }^{36}$ Functional screening for the selfrenewal determinants in
ES cells revealed that Nanog expression is crucial to maintain ES cell identity. ${ }^{36}$ Hyslop et al reported that small interfering RNA (siRNA)-mediated downregulation of Nanog in human embryonic stem cells induces a pro-extraembryonic lineage differentiation, evidenced by the upregulated endoderm- and trophectoderm-associated genes, ${ }^{37}$ suggesting that Nanog acts as a gatekeeper of pluripotency in human embryonic development.

The expression of Nanog has been shown to be regulated by Oct4/Sox 2 heterodimers, in which Oct4/Sox 2 binds to the octamer/sox elements within the Nanog proximal promoter region and induces Nanog transcription. ${ }^{51,52}$ Although the Oct4/Sox 2 complex may seem to locate in a higher position in the hierarchical regulatory network of ES cells, Nanog possesses unique properties that divert from the other key stemness transcriptional factors. The leukemia inhibitory factor (LIF) has been utilized to maintain the symmetrical selfrenewal of mouse ES cells. ${ }^{53}$ Through activating its downstream effector, signal transducer and activator of transcription 3 (STAT3), the LIF/STAT3 pathway has been proved to be indispensable in the maintenance of pluripotent state of mouse ES cells. Several key transcriptional factors, including Oct4 and Sox2, are shown to be functionally dependent on LIF-STAT3. Constitutively activated Oct4 from an exogenous promoter in ES cells still required LIF for inducing selfrenewal in ES cells. ${ }^{54}$ In 2003, two independent groups, Chambers et al and Mitsui et al, applied different strategies to screen for critical factors that can maintain ES cell pluripotency independently of the LIF-STAT3 pathway and found Nanog. ${ }^{35,36}$ Their reports demonstrated that Nanog overexpression relieves ES selfrenewal from dependence on the activity of LIF-STAT3 pathway. Moreover, Chambers' report showed that Nanog is expressed in Oct4-deficient embryos, and Nanog overexpression does not revert the differentiation program of ES cells triggered by Oct4 downregulation. ${ }^{36}$ These results suggest that Nanog is not just a downstream of Oct4, and Nanog and Oct4 work in concert to support stem cell potency and selfrenewal.

\section{Nanog, tumorigenicity, and cancer stemness}

Expression of Nanog has been detected by several groups in germ cell tumors as well as other tumors, including breast, cervix, oral, kidney, prostate, lung, gastric, brain, and ovarian cancer. ${ }^{10,34,55-65}$ Strong expression of Nanog is shown as an indicator of a poor prognosis for ovarian serous carcinoma, colorectal, and breast cancer patients. ${ }^{66-68}$ In oral squamous cell and lung adenocarcinoma, higher expression of Nanog, 
along with Oct4, was associated with advanced cancer stage and shorter patient survival rate. ${ }^{34,63}$

The expression level of Nanog has been shown to be higher in cancer stem cells than non-stemness cancer cells in several types of cancers. ${ }^{4,5,10,31,32,65,69,70}$ In some cases, Nanogpositive cancer stem cells only comprise less than $2 \%$ of the total cancer cell population. ${ }^{5}$ The difference may be due to the fact that several key factors in the stemness network, such as Oct4 and Sox2, are also increased in CSC, which increases stemness-related genes like Nanog; or, it is possibly because of the increased activity or expression of upstream regulators of Nanog, such as Hedgehog, ${ }^{71}$ Ezh $2,{ }^{72}$ and several miRNAs. This question, as well as the causal relationship between elevated stemness pathways and CSC properties, is still under investigation in this field. Moreover, a direct regulatory link between Nanog and CSC surface markers is yet to be clarified. There are, however, several correlation studies demonstrating that cancer cells expressing high levels of the CSC surface marker would possess higher levels of stemness genes like Nanog. For example, CD133+ or CD44+ cancer cells express significant higher level of Nanog in comparison to $\mathrm{CD} 133$ - or CD44+ ones, respectively. ${ }^{73-75}$ On the other hand, Nanog induction in prostate cancer cell lines results in upregulation of CD133 and ALDH1. ${ }^{70}$

Functional studies have demonstrated that Nanog is not only a CSC marker, but also promotes CSC-like characteristics in several cancers. For example, ectopic overexpression of the NANOGP8 gene in prostate cancer cells enhanced clonal growth and tumor regenerative capacity, ${ }^{70}$ and the activation of embryonic $N A N O G$ gene drives a subpopulation of colorectal cancer cells to adopt a stem-like phenotype. ${ }^{5}$ Overexpression of Nanog also increased drug-resistance capacity in breast cancer cell lines. ${ }^{70}$ The Nanog protein can bind to the promoter region of cyclin D1 and regulate cell cycle and proliferation. ${ }^{76,77}$ Moreover, Nanog positively regulates cancer cell motility and tumor metastasis capability. Nanog was found highly expressed in ovarian cancer cell lines with metastasis-associated property and in clinical samples of metastatic foci. Knockdown of Nanog impeded cell proliferation, migration, and invasion. ${ }^{78}$

Recently, Noh et al reported that Nanog activates the Akt signaling pathway through T-cell leukemia/lymphoma protein 1 A (Tcl1a), and hyperactivation of the Nanog/Tcl1a/Akt signaling axis is conserved across multiple types of human cancer. ${ }^{79}$ They demonstrated that the Nanog-mediated activation of Akt pathway renders cancer cells adapted to host immune system and leads to a successful escape from the immune-mediated clearance. Therefore, the failure of cancer vaccination may be due to a Nanog-dependent evolution of tumor cells toward an immune-resistant and stem-like phenotype. ${ }^{80}$ Apart from cancer cells, Gu et al showed that the cancer stromal cells that express high levels of cytoplasmic Nanog may promote human cervical cancer progression, ${ }^{81}$ suggesting a role of Nanog in regulating the cross talk between cancer cells and cancer associated stromal cells.

\section{Upstream regulators of Nanog in cancers}

In ES cells, Nanog is involved in a complicated stemness regulatory network in cooperation with other key transcriptional factors, such as Oct4, Sox2, and Lin 28, to precisely balance between pluripotency and differentiation tendency. Kalmar et al reported that Nanog presents a transcriptional fluctuation between low and high expression level in ES cells. ${ }^{82}$ They proposed that the dynamic distribution of Nanog is crucial for ES cells to maintain the undifferentiated state and yet possess the potential to be differentiated without marking definitive commitment if a proper differentiation signaling strikes the cells. The tightly regulated Nanog seems to be a key switch that determines the fate of ES cells.$^{83} \mathrm{In}$ cancer cells, Nanog is usually overexpressed, especially in the malignant, high grade, poorly differentiated ones, and the fluctuation of Nanog expression in cancer cells has so far not been reported. It seems that deregulated and abnormal Nanog expression drives the cells to a reprogramming-like process but fails to keep cells in the track that leads to an ordinary stemness state, resulting in cells going on a diverted route that ends with upregulation of several downstream signalings involving in tumorigenesis.

Despite the Oct4 and Sox2 stemness factors that are involved in ES regulatory networks, many regulators, including microRNAs, transcription factors, and kinases, have been reported to mediate the silencing or overexpression of Nanog and thus regulate the stemness and malignant transformation, as well as CSC-like phenotypes in cancer cells (Table 1). To date, most of the regulatory mechanisms on Nanog are focused on the transcription level, though accumulating data have also emphasized the importance of post-transcriptional and translational regulation of Nanog.

\section{p53}

p53 is a stress-activated transcription factor that prevents the proliferation of genetically damaged cells. Given that p53 is a key mediator regulating programmed cell death (apoptosis) and cell-cycle related pathways, such as activating cell-cycle checkpoint and promoting cell senescence, it has been well 
Table I Upstream regulators of Nanog

\begin{tabular}{lll}
\hline Targets & Mediated cell functions & References \\
\hline STAT3 & Maintenance of pluripotency. & $4,93,95$ \\
Ezh2 & $\begin{array}{l}\text { Epigenetic regulation of Nanog, } \\
\text { selfrenewal. }\end{array}$ & 72 \\
Hedgehog & Selfrenewal, tumorigenicity. & 32,7 I,89 \\
TLR4 & Tumor formation. & 132 \\
P53 & Differentiation, CSC properties & $32,84,85$ \\
& acquirement. & \\
Esrrb & Maintaining Nanog expression. & III,II2 \\
HIF2a & Enhances Nanog and CSC & 133 \\
& properties under hypoxia. & \\
PI3K/Akt & Tumorigenesis, cell survival, & $33,115,12$ I, I34 \\
& and selfrenewal. & \\
\hline
\end{tabular}

Abbreviations: CSC, cancer stem cells; Esrrb, estrogen-related receptor $\beta$; PI3K, phosphatidylinositide 3-kinase; STAT3, signal transducer and activator of transcription 3; Ezh2, enhancer of zeste homolog 2; HIF2a, hypoxia inducible factor 2a; Akt, protein kinase B; TLR4, toll-like receptor 4 .

accepted as a major player for tumor suppression. Loss or inactivation of $\mathrm{p} 53$ facilitates the clonal expansion of aberrant cells and leads to genomic instability. During the last decade, a direct involvement of p53 in the stemness regulatory network has emerged and draws much attention in the fields of both stem cell and cancer research. In mouse ES cells, p53 directly binds to Nanog promoter through two consensus p53-binding motifs and suppresses Nanog transcription in response to DNA damage. ${ }^{84}$ The DNA damage-induced and p53-mediated suppression of Nanog, which depends on the phosphorylation at serine 315 of $\mathrm{p} 53$, results in reduced selfrenewal and enhanced differentiation tendency of mouse ES cells. ${ }^{85}$ Through inducing differentiation via Nanog suppression, $\mathrm{p} 53$ protects the genomic intactness and maintains genetic stability in ES cells. The p53-Nanog regulatory signaling was also implicated in cancer cells, especially in brain CSCs. Nanog was shown to induce the CSC-like properties in primary p53-defecient mature mouse astrocytes, but not in the astrocytes with intact $\mathrm{p} 53,{ }^{86}$ suggesting $\mathrm{p} 53$ as the gatekeeper, not only preventing normal cells from tumor transformation, but also preventing cancer cells from further acquirement of CSC properties. These findings also echo the discovery that, during the reprogramming process, suppression of p53 is essential to enhance the generation of induced pluripotent stem (iPS) cells. ${ }^{87}$ Hong et al reported that loss of p53 facilitates cellular immortalization, and suggested that the p53-p21 pathway serves as a barrier in iPS cell generation as well as tumorigenicity. ${ }^{87}$ Given that expression of Nanog improves the cloning efficiency of human ES cells, it could therefore increase the survival rate of early reprogrammed cells. ${ }^{88}$ The suppressive effect of $\mathrm{p} 53$ on reprogramming and cancer-stemness could partially count on its negative regulation of Nanog. Since approximately $>50 \%$ of cancers harbored p53 mutation or deficiency, blockade of Nanog, and, therefore, Nanog mediated regulatory circuits, would be a potential method to prevent tumor malignancy.

\section{Hedgehog}

Nanog and hedgehog are both essential regulators of stemness properties by promoting selfrenewal in ES cells during the early stage of embryonic development as well as in cancer progression. The sonic hedgehog and its downstream transcription factor, GLI family zinc finger 1 (Gli1), have been shown to promote CSC survival, tumor growth, and the expression of stem-like signature in human glioma cells, ${ }^{89}$ suggesting a direct regulatory role of hedgehog-Gli1 in the core stemness network. Indeed, Po et $\mathrm{al}^{71}$ later on reported a direct regulatory pathway between hedgehog signaling and Nanog. They showed that the downstream effectors of hedgehog activity, Gli1 and GLI family zinc finger 2, directly bind to the cis-regulatory sequences of the $N A N O G$ gene in both mouse and human neural stem cells, and thus activate Nanog transcription, which is essential for hedgehog-induced selfrenewal in neural stem cells. ${ }^{71}$ They suggested a model in which Nanog is a critical mediator of hedgehog effect on neural stem cells. This regulation does not go through p53; on the other hand, since p53 is known to suppress sonic hedgehog signaling, they proposed that p53 might inhibit Nanog transcription partially through the suppression of hedgehog-Gli pathway. ${ }^{71}$ Moreover, Zbinden et al demonstrated a positive regulatory loop between Nanog and sonic hedgehog signaling; knockdown of Nanog decreased the endogenous activity of Gli1 whereas the Nanog mRNA levels were modulated by hedgehog pathway. ${ }^{32}$ This positive feedback loop is negatively regulated by p53, and suppression of Nanog enhanced p53 and repressed Gli1, suggesting that Nanog is situated in a neat balance between p53 and hedgehog signaling. Deregulation of the balance between p53 and hedgehog signaling would result in aberrant expression of Nanog, which further feedback to both p53 and hedgehog signalings and resulted in either acquirement of stem-like properties of cells or shrinking of the CSC population.

\section{STAT3}

STAT3 is one of the major effectors of the LIF pathway, which is essential for the maintenance of the pluripotency in ES cells. A microarray analysis in mouse ES cells showed that 14 out of the 22 STAT3 target genes that contribute to the maintenance of an undifferentiated state were also regulated by Nanog, suggesting a functional redundancy and cooperation between STAT3 and Nanog. ${ }^{90}$ In some cases, Nanog and STAT3 
were found to bind to and synergistically activate STAT3dependent promoters. ${ }^{91}$ The direct interaction between Nanog and STAT3 was found by Bourguignon et al; ${ }^{92}$ they showed the Nanog-STAT3 complex in head and neck squamous cell carcinoma cells. The complex translocates to the nucleus and transcriptionally activates their common targets. ${ }^{92}$ On the other hand, LIF-induced phosphorylation of STAT3 directs the binding of STAT3 to the enhancer of NANOG gene and, thus, results in upregulation of Nanog expression in ES cells. ${ }^{93}$ Moreover, it is also suggested that STAT3 regulates Nanog expression through methylation, as inhibiting the Janus kinase/ STAT3 activity blocks demethylation of Nanog during the reprogramming process, along with upregulation of DNA methyltransferase 1 and histone deacetylases. ${ }^{94}$ This indicates that, apart from cooperative partner, STAT3 may also regulate Nanog expression through epigenetic modification. The fact that LIF/STAT3 pathway promotes Nanog expression in ES and cancer cells suggests Nanog as an important mediator for LIF-dependent maintenance of pluripotency, which may explain why Nanog-maintained pluripotency of cultured ES cells does not require the addition of LIF. Moreover, through activating STAT3, molecules like CD24 ${ }^{4}$ and E-cadherin, ${ }^{95}$ are also shown to modulate Nanog expression, both in ES cells and in cancer cells.

\section{microRNAs}

miRNAs are short RNAs that direct the degradation of messenger RNA or disruption of messenger RNA translation in a sequence-dependent manner. Through targeting the core stemness factors, such as Oct4, Nanog, and Sox2, the up- and downregulation of miRNAs, such as miR134, miR296, and miR470 play roles in modulating the selfrenewal, pluripotency, and differentiation of ES cells. ${ }^{96}$ There are increasing reports identifying miRNAs that target Nanog and mediate the malignant progression in cancer cells or CSCs. miR134 was first found directly targeting Nanog in mouse ES cells, through which it promotes mouse ES cells differentiation toward ectodermal lineages. ${ }^{97}$ The same phenomenon was also found in glioblastoma cells; overexpression of miR134 reduced the proliferation, invasiveness, and migration capability, and promoted apoptosis of glioblastoma cell lines through directly suppressing Nanog expression. ${ }^{98}$ Enhanced expression of miR214 has been found in several human malignancies ${ }^{99,100}$ and was associated with late-stage and high-grade ovarian cancer. ${ }^{101} \mathrm{Xu}$ et al ${ }^{101}$ reported that Nanog level was induced by overexpressed miR214 in p53wildtype ovarian cancer cell lines, but not in $\mathrm{p} 53$-mutant ones, linking miR214 with the p53/Nanog pathway. They further showed p53 as a direct target of miR214, and demonstrated that, through suppressing p53 and consequently elevating Nanog, miR214 increased ovarian cancer cell stemness. ${ }^{101}$ In glioblastoma, miR302-367 cluster was found upregulated when suppressing the stemness of CSC. This miRNA cluster was shown to suppress the stemness properties (like stemness signature, selfrenewal, and cell infiltration) of glioblastoma CSC through disrupting the sonic hedgehog-Gli1-Nanog signaling pathway. ${ }^{102}$ These reports emphasize a role of Nanog in miRNAs-mediated regulation of CSC properties, and therefore suggest Nanog as a potential target to suppress the increased cancer stemness due to deregulated miRNAs.

\section{Downstream targets and cellular functions of Nanog in cancer}

Nanog is involved in several cellular functions that positively affect tumor development and progression, such as cell proliferation, cell cycle progression, motility, apoptosis, and the cross-communication between cancer cells and their surrounding stromal cells. In some cases, ectopic overexpression of Nanog is sufficient to induce malignant transformation. ${ }^{103,104}$ Investigators have endeavored to discover through which mechanisms Nanog regulates tumorigenesis. The identified downstream targets of Nanog are listed in Table 2.

\section{Cell proliferation and cell cycle}

Nanog is well-known for being involved in the regulation of selfrenewal in ES cells. In cancer cells, aberrant expression of Nanog has been linked to increased proliferation rate in vitro and tumor growth in vivo. We previously showed that overexpression of Nanog, along with Oct4, increased

Table 2 Downstream modulators of Nanog

\begin{tabular}{|c|c|c|}
\hline Targets & Mediated cell functions & References \\
\hline Cyclin DI & $\begin{array}{l}\text { Cell cycle progression, G0/GI } \\
\text { arrest, and proliferation. }\end{array}$ & 76,77 \\
\hline$A B C B I$ & Chemoresistance. & $34,107-109$ \\
\hline GDF3 & Growth and differentiation. & 105 \\
\hline Dnmtl & $\begin{array}{l}\text { Maintenance of selfrenewal and } \\
\text { undifferentiated state. }\end{array}$ & 135 \\
\hline E-cadherin & Migration and invasion. & 78 \\
\hline Foxjl & Migration and invasion. & 78 \\
\hline Tclla & Immune evasion. & 79 \\
\hline Dkkl & Paracrine communication with stroma. & 124 \\
\hline FAK & $\begin{array}{l}\text { CSC proliferation and motility, tumor } \\
\text { survival. }\end{array}$ & 84,122 \\
\hline
\end{tabular}

Abbreviations: $A B C B I, A T P$-binding cassette sub-family $B$ member I; CSC, cancer stem cells; FAK, focal adhesion kinase; Tclla, T-cell leukemia/lymphoma protein IA; GDF3, growth differentiation factor-3; Dnmt I, DNA (cytosine-5)-methyltransferase I; FoxJI, forkhead box protein JI; Dkk I, dickkopf-related protein I. 
clonogenic growth and spheroid body formation of lung adenocarcinoma cells. ${ }^{34}$ Knockdown of Nanog/Oct4 in lung cancer, ${ }^{34}$ or Nanog alone in breast cancer cells, ${ }^{76}$ suppressed clonogenic growth and proliferation. A global gene expression profile screening in Nanog siRNA-transfected embryonal carcinoma cells suggested the involvement of Nanog in cell cycle-signaling pathway. ${ }^{77}$ This group reported that with Nanog knockdown alone, several cell cycle-related genes (such as Cyclins D1, D2, D3, and E1 as well as cyclindependent kinase 1 and 6) as well as p53-related signaling pathway (such as Bcl6 and Atf3) were downregulated, suggesting a role of Nanog in cell cycle and survival. ${ }^{77}$ In breast cancer cells, Han et al found that knockdown of Nanog results in inhibited cell proliferation, G0/G1 arrest of cell cycle, and suppressed expression of cyclin D1 and oncogene c-Myc. ${ }^{76}$ They further demonstrated that Nanog directly binds to the minimal promoter region of cyclin D1, transcriptionally regulates its expression, and thus drives the cell cycle moving forward and accelerates cell proliferation. ${ }^{76}$ Growth differentiation factor-3, a member of the transforming growth factor $\beta$ superfamily, is another direct transcriptional target of Nanog that mediates Nanog-dependent regulation of growth and transformation in embryonic carcinoma. ${ }^{105}$ However, the existence of this regulation, as well as its physiological effects, in other cancer models are still elusive. Further clarification of the mechanism through which Nanog regulates cell proliferation is still needed to shed light on the role of Nanog in tumor growth.

\section{Migration and invasion}

Overexpression of Nanog is associated with tumor metastasis in several types of cancer. ${ }^{59,61,66-68,73,76,106}$ In ovarian cancer patient samples, increased nuclear Nanog expression was significantly associated with high-grade, serious histological subtypes, and poor disease-free survival. ${ }^{78}$ The correlation between Nanog overexpression and advanced stage of cancer or metastatic incidence indicates a crucial role of Nanog in tumor progression. Stable knockdown of Nanog in ovarian cancer cell lines resulted in increased E-cadherin, FOXO1, FOXO3a, FOXJ1, and FOXB1 mRNA levels, whereas ectopic Nanog overexpression decreased them. ${ }^{78}$ It is further claimed that Nanog-mediated cell migration and invasion involved its regulation of FOXJ1 and E-cadherin, ${ }^{78}$ though whether Nanog directly regulates their expression is still unclear. We previously demonstrated that co-overexpression of Nanog and Oct4 in lung adenocarcinoma cells induces the level of Slug through a transcriptional regulation, leading to enhanced cell motility and tumor metastasis. ${ }^{34}$ We found that
Nanog alone is able to induce Slug transcription, an important transcription factor of epithelial-mesenchymal transition and tumor invasion.

\section{Chemoresistance}

The chemoresistant property of CSC has been associated with the expression of several stemness factors such as Oct4 and Nanog. ${ }^{5,31,34,70,107}$ In human esophageal cancer, overexpression of Nanog promoted cisplatin resistance and decreased the proportion of cells undergoing apoptosis process. ${ }^{107} \mathrm{We}$ showed in lung adenocarcinoma cells that ectopic overexpression of Nanog and Oct4 enhanced the mRNA level of ATP-binding cassette sub-family B member 1 (ABCB1) - a membrane-bound transporter involved in the ATP-dependent exclusion of cellular toxic agents - leading to a high tolerance of lung adenocarcinoma cells to cisplatin treatment. ${ }^{34}$ Similar phenomena were also found in oral squamous cell carcinoma, where increased Nanog and Oct4 expression was correlated with a cisplatin-resistant phenotype as well as cancer recurrence; ${ }^{108}$ the chemoresistant cells also expressed high level of the drug-resistance-related gene $A B C G 2$. In fact, Bourguignon et al reported a Nanog-STAT3-ABCB1 signaling pathway in breast and ovarian cancer that mediates the resistance against several chemotherapeutic drugs. ${ }^{109}$ In their report, they showed that Nanog forms a complex with the STAT3 transcription factor in the nucleus and leads to STAT3specific transcriptional activation and $\mathrm{ABCB} 1$ gene expression. ${ }^{109}$ These data revealed a direct regulatory link between Nanog and the drug-resistance mechanism in cancer cells. Moreover, there are some traits of indication that Nanog may also regulate p53-related signaling and negatively affect the pro-apoptosis mechanisms. ${ }^{77}$ On the other hand, an earlier report suggested that p53-dependent signaling pathway may directly suppress Nanog expression in DNA-damaged ES cells in order to maintain the gene stability. ${ }^{110}$ Given that Nanog is involved in p53-dependent pro-apoptosis pathway and $\mathrm{ABC}$ genes expression, it is not surprising why CSCs are sustainable to apoptosis and drug treatments.

\section{Immune tolerance}

Immune-related cancer therapy, such as cancer vaccination, was once thought to be a specific method targeting cancer cells. However, positive and promising outcomes in clinical trials of this approach are so far still lacking. This may partially, if not entirely, be due to the capability of cancer cells to adapt themselves to the host immune system in order to avoid the killing and apoptosis mediated by the $\mathrm{CD}^{+}$cytotoxic $\mathrm{T}$ lymphocytes. ${ }^{79,80}$ Noh et al found that 
the application of cancer vaccination resulted in increased Nanog expression and stemness properties in tumor cells. ${ }^{80}$ Though it was uncertain whether the increase was due to an immune selection or induction, the elevated Nanog drove tumor cells toward an immune-resistant state, rendering cells tolerant to the killing by cytotoxic T lymphocytes. ${ }^{80}$ The same group further demonstrated that the Nanog-dependent immune resistance in tumor cells is mediated through a Tclla/ Akt pathway. ${ }^{79}$ The hyperactive Nanog/Tclla/Akt pathway not only increased stem-like phenotype in tumor cells but also promoted an immune evasion. These reports reveal an important role of Nanog in regulating the interaction between cancer cells and host immune cells, in which Nanog promotes the disguise of cancer cells to avoid the attack from immune system. Interestingly, delivery of siRNA against Nanog in these tumor cells reversed the immune-resistant phenotype and strongly retarded tumor growth. Therefore, it is suggested that targeting Nanog is a potential strategy for achieving immune-based therapy.

\section{Cross talk between Nanog and oncogenic pathways ESRRB}

The orphan nuclear receptor estrogen-related receptor $\beta$ (Esrrb) that modulates the estrogen signaling pathway is a vital component of the core pluripotency network in embryonic stem cells (ESCs). Previously, Esrrb was reported to initiate the expression of Nanog in ESCs. Van den Berg et al demonstrated that, through direct interaction with Oct4, Esrrb was directed to the Oct4 responsive element within Nanog promoter and induce the expression of Nanog, leading to increased self-renewal in ESC. ${ }^{11}$ Moreover, the Esrrb is not only an upstream regulator of Nanog but also a direct target of Nanog. Nanog binds to Esrrb locus, recruits RNA polymerase II to the Esrrb promoter, and increases Esrrb gene expression. ${ }^{12}$ Nanog and Esrrb proteins also interact directly in ESCs, and share overlap downstream targets. ${ }^{112}$ Furthermore, Esrrb, like Nanog, presented a mosaic pattern in ESCs, and the mosaic patterns of the two molecules largely overlap. ${ }^{11}$ Nanog and Esrrb may act to reinforce expression of the reciprocal genes through a positive feedback loop. Fluctuation of the Nanog-Esrrb feedback loop confers ESCs' pluripotency and differentiation potential without being committed to specific lineages. Although the mutual dependence between Nanog and Esrrb was mainly discovered in ESCs, it is possible that the feedback circuit could exist in cancer or CSCs, as Nanog and accumulating members of estrogenrelated receptors are implicated in cancer malignancies.
Investigations into the involvement of the Nanog-Esrrb circuit in CSC properties may shed some light on how Nanog mediates selfrenewal in CSCs.

\section{Receptor tyrosine kinases and Akt-dependent pathways}

Deregulation of receptor tyrosine kinases is a common phenomenon in cancer cells. The epithelial growth factor receptor (EGFR) is frequently found overexpressed or mutated in several types of cancer including lung, breast, and brain. In some reports, EGFR seems to be involved in the acquisition of stemness properties in cancer cells. ${ }^{113-115}$ Previous reports, and our unpublished data, showed that activation of EGFR pathway, either through EGF treatment or ectopic overexpression of active EGFR, resulted in enhanced Nanog expression both at its protein and mRNA levels. ${ }^{16,117}$ This data may explain how EGFR regulates stem-like properties in cancers. Shan et al demonstrated that Nanog regulates selfrenewal of CSCs through the insulin-like growth factor receptor (IGF-1R) pathway in human hepatocellular carcinoma, and suppression of IGF-1R decreased the expression of Nanog in return. ${ }^{33}$ The role of the phosphatidylinositide 3-kinase (PI3K) pathway in regulating Nanog expression is well known in ES cells. ${ }^{118,119}$ In lung adenocarcinoma cells, the IGF-1R activation leads to transcriptional activation of Nanog via the $\mathrm{PI} 3 \mathrm{~K} / \mathrm{Akt} / \mathrm{GSK} 3 / \beta$-catenin cascade. ${ }^{120}$ In mouse ES cells, loss of phosphatase and tensin homolog, a tumor suppressor gene acting through inhibiting the PI3K pathway, causes tumor initiation following differentiation because of failed repression of Nanog. ${ }^{121}$ These data demonstrated a closely related regulation between stemness and oncogenic pathways and the crucial role of Nanog in this cross talk, rendering Nanog as a prospective target of cancer therapy.

\section{FAK signaling}

Nanog also cross talks with the focal adhesion kinase (FAK), which is known to play a significant role in tumor survival. Nanog directly binds to the promoter region of FAK and enhances its transcription, whereas FAK protein interacts with Nanog and mediates Nanog phosphorylation. ${ }^{122}$ Phosphorylated Nanog is distributed in the nucleus and is essential to mediate tumor invasion in several cancer cells. ${ }^{122}$

\section{Nanog and cancer-stroma communication}

There has been an accumulating interest in focusing on the role of the microenvironment surrounding cancer cells in regulating cancer progression and CSC property acquisition. We previously showed that the Nanog expression 
level in lung adenocarcinoma cells could be suppressed by cocultured bone marrow-derived mesenchymal stem cell (MSC) or its conditioned medium. This suppression is, at least in part, due to the secreted oncostatin M from MSC paracrinally inhibiting Nanog, Snail, and Slug in lung adenocarcinoma cells through a STAT1 (signal transducer and activator of transcription 1)-dependent pathway. ${ }^{123}$ The suppressed Nanog, Snail, and Slug led to reduced cell motility in vitro and tumor metastasis in vivo. These data suggests that Nanog in cancer cells is able to receive extracellular signaling from cancer microenvironment.

Apart from promoting cancer stemness in cancer cells, Nanog was also found to mediate MSC and affect the MSCdependent suppressive effect on tumor growth. ${ }^{124} \mathrm{Zhu}$ et $\mathrm{al}^{124}$ showed that MSC inhibits cancer cell proliferation by secreting dickkopf-1. They further showed that Nanog binds to the promoter of dickkopf-1 in MSC and drives its transcription as well as increases its secretion. Therefore, MSCs with a high expression level of Nanog may possess antitumor ability. It has been suggested that the pluripotent status of MSC mediates its antitumor effect; MSC suppressed tumor cells only when they were precursors of matrix cells. ${ }^{125}$ In agreement, the expression level of Nanog may determine the antitumor capacity of MSCs. Furthermore, Nanog was also reported to regulate the expression and secretion of TGF- $\beta 1$, TGF- $\beta 2$, and TGF- $\beta 3$ in MSC. ${ }^{126}$ These data suggest a role of Nanog in regulating the composition of paracrine factors in cancer microenvironments. Caution should be taken in terms of which cell is targeted when suppressing Nanog for cancer therapy.

\section{Targeting Nanog in cancer cells}

Targeting gene therapy is a promising therapeutic method to specifically fix the genetic disorder in diseases such as cancers. Through delivery of exogenous DNA or RNA sequence into host cells, we are able to enhance or suppress the expression of a selected gene to counteract the deregulated signaling pathway. Theoretically, there are several advantages to choose Nanog as a therapeutic target. First of all, Nanog cross talks with several well-known oncogenic pathways, which makes it a highly potential candidate to be targeted. Second, Nanog is supposedly not expressed in ordinary differentiated somatic cells; therefore, off-target effects of Nanog-targeting should be limited. Finally, according to the cellular functions mediated by Nanog downstream effectors, specific suppression of Nanog inhibits CSC functions, reduces tumor growth and metastasis, prevents the resistance to chemotherapeutic drugs, and enhances the immune surveillance of the host and apoptosis of the cancer.

There is an accumulation of evidence demonstrating the therapeutic potential of targeting Nanog in several cancer cells. For example, using RNAi-mediated Nanog knockdown, Jeter et al observed a reduced growth of subcutaneous xenograft tumors in vivo. ${ }^{45}$ They pre-transfected shNanog in prostate, colon, and breast cancer cell lines before injecting the cells in NOD/SKID mice and found that the shNanog-transfected cells presented reduced long-term clonogenic growth, proliferation, and tumor size in mice. Similar phenomena were also observed in other reports with different cancer models, though how Nanog regulated cell proliferation and tumor growth had not been clear until cell cycle-related molecules, such as cyclin D1 and cyclin-dependent kinases, were identified as Nanog transcriptional targets in CSCs recently. ${ }^{76,77}$ Apart from reducing tumor growth, shNanog was also found to suppress tumor metastasis in a mouse model. Zhang et al showed that colorectal cancer cells transduced with shNanog failed to form grossly visible or microscopic hepatic liver colonies in mice, compared with parental cells. ${ }^{31}$ They claimed that shRNA-mediated inhibition of Nanog gene expression is associated with both inhibition of experimental tumor growth and metastasis, as well as malignant phenotype and cancer stemness.

Targeting Nanog in cancer cells showed a synergistic therapeutic effect with chemotherapeutic drugs such as cisplatin. siRNA-mediated knockdown of Nanog increased the sensitivity of esophageal cancer cells to cisplatin treatment and induced cell apoptosis. ${ }^{127}$ Although this effect still lacks in vivo evidence, it is not surprising that inhibition of Nanog would decrease drug resistance of cancers since Nanog has been linked to chemoresistance mechanisms through ABCB1 and p53. ${ }^{32,34,85,109}$ Furthermore, inhibition of Nanog in mice repressed the immune evasion of the tumor cells and increased the therapeutic effect of cancer vaccination. Delivery of siNanog into tumor-bearing mice increased tumor vulnerability to immune surveillance and suppressed tumor growth. ${ }^{80}$ It seems that combining Nanog knockdown with current therapeutic methods, like cisplatin and cancer vaccination, would largely improve the therapeutic outcome in the mouse model.

There are still issues, however, that need to be clarified before further development of siNanog or shNanog as a therapeutic method. First, although experimental evidence has shown a promising therapeutic efficacy of Nanog knockdown in controlling tumor growth, metastasis, 


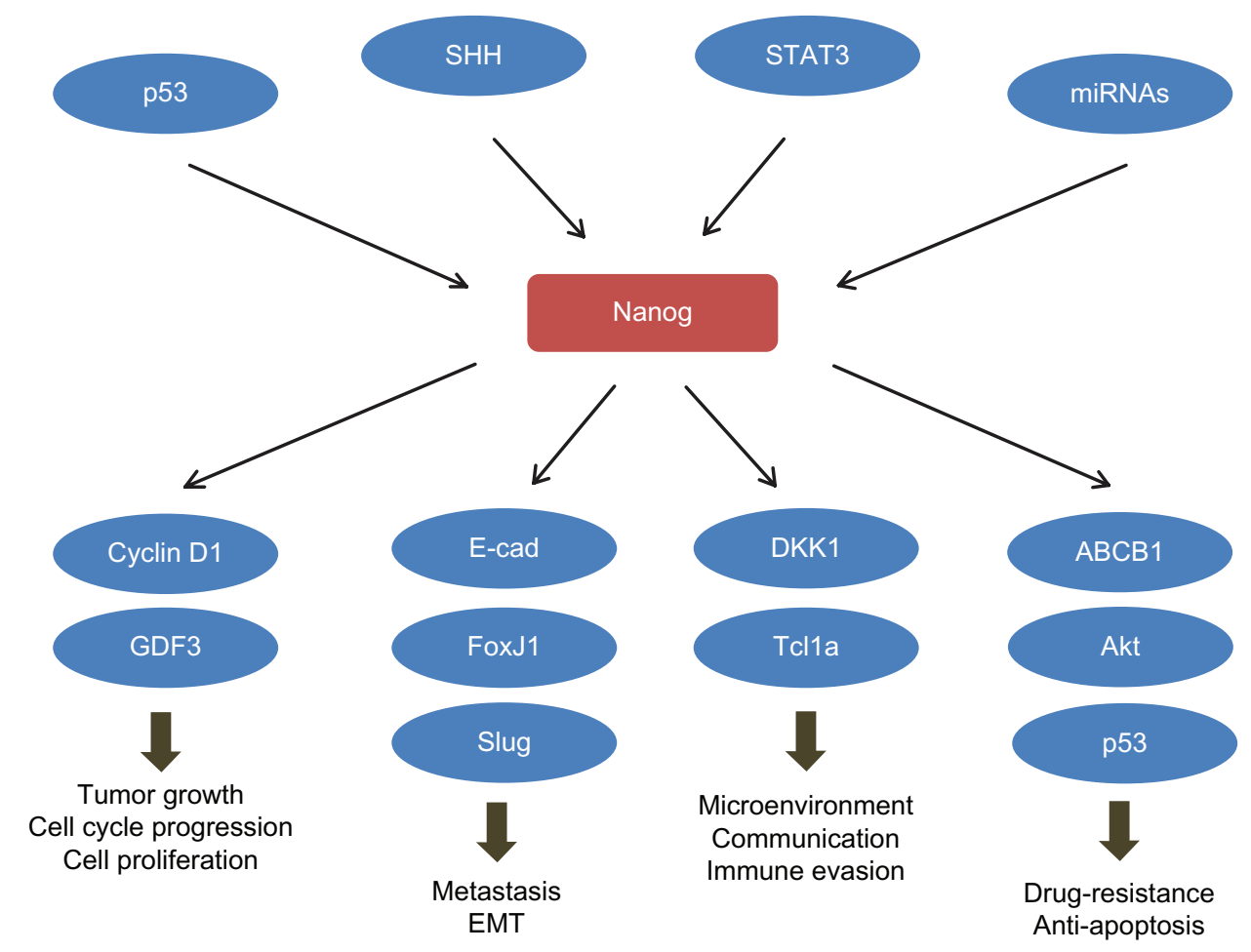

Figure I Nanog plays a central role in the cancer signaling network.

Abbreviations: ABCBI, ATP-binding cassette sub-family B member I; E-cad, E-cadherin; miRNAs, microRNAs; STAT3, signal transducer and activator of transcription 3; Tclla, T-cell leukemia/lymphoma protein IA; SHH, sonic hedgehog; GDF3, growth differentiation factor-3; DKKI, dickkopf-related protein I; Akt, protein kinase B.

drug-resistance, and immune evasion in animal models, its efficacy in a model that is more close to clinical operations is still under investigation. For example, delivering siNanog or shNanog in tumor-bearing animals with appropriate delivery methods and reasonable doses would reveal how realistic it is to use Nanog-targeting as a cancer treatment. Second, the optimal delivery methods for siNanog or shNanog need to be identified. This would affect the side effects they may cause and the stability of delivered genes in cells. It has to be noted that adeno-associated virus ${ }^{128}$ and nanoparticles ${ }^{129,130}$ have been implicated as therapeutic delivery agents with promising efficacy. Moreover, conjugating nuclear localization sequence to the double-stranded DNA encoding for siNanog or shNanog could possibly enhance their nuclear delivery, as reported previously. ${ }^{131}$ As well as choosing an appropriate delivery method, modification of the RNAi construct structure might also be a way to improve delivery efficacy. Third, being able to direct the Nanog RNAi to the cancer site would be a challenge. Whether to combine specific cancer or CSC markers as well as the selection of markers will need further evaluation. Finally, Nanog-targeting may be operated alone or in combination with current treatment methods such as chemotherapy and cancer vaccination. The synergistic effects still need to be validated in vivo.

\section{Conclusion}

Nanog determines the cell-fate both in ESC and CSC. Activating Nanog at an inappropriate time would cause CSC rather than ESC-like iPS. Failure to repress Nanog during the differentiation process in mouse pluripotent stem cells results in tumor initiation. Moreover, Nanog cross talks with several signal pathways both pro-oncogenic, such as PI3K and STAT3, and tumor-suppressive, such as p53 and PTEN (Figure 1). Nanog also mediates the communication between cancer cells and their surrounding stromal and immune cells; Nanog expression level in both cancer and stromal cells determines the direction of the paracrine effects between them. These crucial roles of Nanog make it a center of cancer signaling networks (Figure 1) and a potentially ideal target for cancer treatment. In order to target Nanog in CSCs, developments of appropriate targeting methods, and an understanding of whether to combine with tissue- or CSC-specific markers, would be needed to avoid off-target side effects. It can be foreseen that the selection of suitable markers would be a challenge and it is necessary to investigate this selection. Current attempts of targeting Nanog in prostate, breast, and colorectal cancers have shown promising therapeutic effects in mouse models. In vivo data with experimental 
platforms that are more close to clinical operation are expected to support the therapeutic potential of Nanog in cancer treatment.

\section{Acknowledgments}

We thank Dr Hui-Wen Chen, professor in the Graduate Institute of Toxicology, National Taiwan University, for advice and suggestions during the preparation of the paper. This research was supported by the Department of Health (DOH101-TD-C-111-007) and the National Science Council (NSC101-2321-B-010-011, NSC102-2325-B-010-010), Executive Yuan, Taiwan, Republic of China.

\section{Disclosure}

The authors report no conflicts of interest in this work.

\section{References}

1. Wicha MS, Liu S, Dontu G. Cancer stem cells: an old idea - a paradigm shift. Cancer Res. 2006;66(4):1883-1890; discussion 1895-1886.

2. Visvader JE, Lindeman GJ. Cancer stem cells in solid tumours: accumulating evidence and unresolved questions. Nat Rev Cancer. 2008;8(10):755-768.

3. Jiang F, Qiu Q, Khanna A, et al. Aldehyde dehydrogenase 1 is a tumor stem cell-associated marker in lung cancer. Mol Cancer Res. 2009;7(3): 330-338.

4. Lee TK, Castilho A, Cheung VC, Tang KH, Ma S, Ng IO. CD24(+) liver tumor-initiating cells drive self-renewal and tumor initiation through STAT3-mediated NANOG regulation. Cell Stem Cell. 2011;9(1): $50-63$.

5. Ibrahim EE, Babaei-Jadidi R, Saadeddin A, et al. Embryonic NANOG activity defines colorectal cancer stem cells and modulates through AP1- and TCF-dependent mechanisms. Stem Cells. 2012;30(10): 2076-2087.

6. Bao S, Wu Q, McLendon RE, et al. Glioma stem cells promote radioresistance by preferential activation of the DNA damage response. Nature. 2006;444(7120):756-760

7. Bertolini G, Roz L, Perego P, et al. Highly tumorigenic lung cancer CD133+ cells display stem-like features and are spared by cisplatin treatment. Proc Natl Acad Sci U S A. 2009;106(38):16281-16286.

8. Eramo A, Lotti F, Sette G, et al. Identification and expansion of the tumorigenic lung cancer stem cell population. Cell Death Differ. 2008;15(3):504-514.

9. Prince ME, Sivanandan R, Kaczorowski A, et al. Identification of a subpopulation of cells with cancer stem cell properties in head and neck squamous cell carcinoma. Proc Natl Acad Sci USA. 2007;104(3): 973-978.

10. Bussolati B, Bruno S, Grange C, Ferrando U, Camussi G. Identification of a tumor-initiating stem cell population in human renal carcinomas. FASEB J. 2008;22(10):3696-3705.

11. Singh SK, Hawkins C, Clarke ID, et al. Identification of human brain tumour initiating cells. Nature. 2004;432(7015):396-401.

12. Bonnet D, Dick JE. Human acute myeloid leukemia is organized as a hierarchy that originates from a primitive hematopoietic cell. Nat Med. 1997;3(7):730-737.

13. Al-Hajj M, Wicha MS, Benito-Hernandez A, Morrison SJ, Clarke MF. Prospective identification of tumorigenic breast cancer cells. Proc Natl Acad Sci U S A. 2003;100(7):3983-3988.

14. Galli R, Binda E, Orfanelli U, et al. Isolation and characterization of tumorigenic, stem-like neural precursors from human glioblastoma. Cancer Res. 2004;64(19):7011-7021.
15. Hemmati HD, Nakano I, Lazareff JA, et al. Cancerous stem cells can arise from pediatric brain tumors. Proc Natl Acad Sci U S A. 2003;100(25):15178-15183.

16. Lapidot T, Sirard C, Vormoor J, et al. A cell initiating human acute myeloid leukaemia after transplantation into SCID mice. Nature. 1994;367(6464):645-648.

17. O'Brien CA, Pollett A, Gallinger S, Dick JE. A human colon cancer cell capable of initiating tumour growth in immunodeficient mice. Nature. 2007;445(7123):106-110.

18. Ricci-Vitiani L, Lombardi DG, Pilozzi E, et al. Identification and expansion of human colon-cancer-initiating cells. Nature. 2007;445(7123): $111-115$.

19. Schatton T, Murphy GF, Frank NY, et al. Identification of cells initiating human melanomas. Nature. 2008;451(7176):345-349.

20. Singh SK, Clarke ID, Terasaki M, et al. Identification of a cancer stem cell in human brain tumors. Cancer Res. 2003;63(18):5821-5828.

21. Fillmore CM, Kuperwasser C. Human breast cancer cell lines contain stem-like cells that self-renew, give rise to phenotypically diverse progeny and survive chemotherapy. Breast Cancer Res. 2008;10(2):R25.

22. Wakamatsu Y, Sakamoto N, Oo HZ, et al. Expression of cancer stem cell markers ALDH1, CD44 and CD133 in primary tumor and lymph node metastasis of gastric cancer. Pathol Int. 2012;62(2):112-119.

23. Tirino V, Camerlingo R, Franco R, et al. The role of CD133 in the identification and characterisation of tumour-initiating cells in non-small-cell lung cancer. Eur J Cardiothorac Surg. 2009;36(3): 446-453.

24. Salven P, Mustjoki S, Alitalo R, Alitalo K, Rafii S. VEGFR-3 and CD133 identify a population of CD34+ lymphatic/vascular endothelial precursor cells. Blood. 2003;101(1):168-172.

25. Yin AH, Miraglia S, Zanjani ED, et al. AC133, a novel marker for human hematopoietic stem and progenitor cells. Blood. 1997;90(12): 5002-5012.

26. Saigusa S, Tanaka K, Toiyama Y, et al. Correlation of CD133, OCT4, and SOX2 in rectal cancer and their association with distant recurrence after chemoradiotherapy. Ann Surg Oncol. 2009;16(12):3488-3498.

27. Das B, Tsuchida R, Malkin D, Koren G, Baruchel S, Yeger H. Hypoxia enhances tumor stemness by increasing the invasive and tumorigenic side population fraction. Stem Cells. 2008;26(7):1818-1830.

28. Ho MM, Ng AV, Lam S, Hung JY. Side population in human lung cancer cell lines and tumors is enriched with stem-like cancer cells. Cancer Res. 2007;67(10):4827-4833.

29. Jiang Y, He Y, Li H, et al. Expressions of putative cancer stem cell markers $\mathrm{ABCB} 1, \mathrm{ABCG} 2$, and $\mathrm{CD} 133$ are correlated with the degree of differentiation of gastric cancer. Gastric cancer. 2012;15(4): $440-450$.

30. Fang D, Nguyen TK, Leishear K, et al. A tumorigenic subpopulation with stem cell properties in melanomas. Cancer Res. 2005;65(20): 9328-9337.

31. Zhang J, Espinoza LA, Kinders RJ, et al. NANOG modulates stemness in human colorectal cancer. Oncogene. Epub October 22, 2012.

32. Zbinden M, Duquet A, Lorente-Trigos A, Ngwabyt SN, Borges I, Ruiz i Altaba A. NANOG regulates glioma stem cells and is essential in vivo acting in a cross-functional network with GLI1 and p53. EMBO J. 2010;29(15):2659-2674.

33. Shan J, Shen J, Liu L, et al. Nanog regulates self-renewal of cancer stem cells through the insulin-like growth factor pathway in human hepatocellular carcinoma. Hepatology. 2012;56(3):1004-1014.

34. Chiou SH, Wang ML, Chou YT, et al. Coexpression of oct 4 and nanog enhances malignancy in lung adenocarcinoma by inducing cancer stem cell-like properties and epithelial-mesenchymal transdifferentiation. Cancer Res. 2010;70(24):10433-10444.

35. Mitsui K, Tokuzawa $\mathrm{Y}$, Itoh $\mathrm{H}$, et al. The homeoprotein Nanog is required for maintenance of pluripotency in mouse epiblast and ES cells. Cell. 2003;113(5):631-642.

36. Chambers I, Colby D, Robertson M, et al. Functional expression cloning of Nanog, a pluripotency sustaining factor in embryonic stem cells. Cell. 2003;113(5):643-655. 
37. Hyslop L, Stojkovic M, Armstrong L, et al. Downregulation of NANOG induces differentiation of human embryonic stem cells to extraembryonic lineages. Stem Cells. 2005;23(8):1035-1043.

38. Wang J, Rao S, Chu J, et al. A protein interaction network for pluripotency of embryonic stem cells. Nature. 2006;444(7117):364-368.

39. Kashyap V, Rezende NC, Scotland KB, et al. Regulation of stem cell pluripotency and differentiation involves a mutual regulatory circuit of the NANOG, OCT4, and SOX2 pluripotency transcription factors with polycomb repressive complexes and stem cell microRNAs. Stem Cells Dev. 2009;18(7):1093-1108.

40. Wang J, Levasseur DN, Orkin SH. Requirement of Nanog dimerization for stem cell self-renewal and pluripotency. Proc Natl Acad Sci U SA. 2008;105(17):6326-6331.

41. Pan G, Thomson JA. Nanog and transcriptional networks in embryonic stem cell pluripotency. Cell Res. 2007;17(1):42-49.

42. Booth HA, Holland PW. Eleven daughters of NANOG. Genomics. 2004;84(2):229-238.

43. Zhang J, Wang X, Li M, et al. NANOGP8 is a retrogene expressed in cancers. FEBS J. 2006;273(8):1723-1730.

44. Fairbanks DJ, Fairbanks AD, Ogden TH, Parker GJ, Maughan PJ. NANOGP8: evolution of a human-specific retro-oncogene. G3 (Bethesda). 2012;2(11):1447-1457.

45. Jeter CR, Badeaux M, Choy G, et al. Functional evidence that the self-renewal gene NANOG regulates human tumor development. Stem Cells. 2009;27(5):993-1005.

46. Oh JH, Do HJ, Yang HM, et al. Identification of a putative transactivation domain in human Nanog. Exp Mol Med. 2005;37(3):250-254.

47. Do HJ, Lim HY, Kim JH, Song H, Chung HM. An intact homeobox domain is required for complete nuclear localization of human Nanog. Biochem Biophys Res Commun. 2007;353(3):770-775.

48. Park SW, Do HJ, Huh SH, et al. Identification of a putative nuclear export signal motif in human NANOG homeobox domain. Biochem Biophys Res Commun. 2012;421(3):484-489.

49. Park IH, Zhao R, West JA, et al. Reprogramming of human somatic cells to pluripotency with defined factors. Nature. 2008;451(7175):141-146.

50. Theunissen TW, Costa Y, Radzisheuskaya A, et al. Reprogramming capacity of Nanog is functionally conserved in vertebrates and resides in a unique homeodomain. Development. 2011;138(22):4853-4865.

51. Kuroda T, Tada M, Kubota H, et al. Octamer and Sox elements are required for transcriptional cis regulation of Nanog gene expression. Mol Cell Biol. 2005;25(6):2475-2485.

52. Do HJ, Lee WY, Lim HY, et al. Two potent transactivation domains in the C-terminal region of human NANOG mediate transcriptional activation in human embryonic carcinoma cells. J Cell Biochem. 2009;106(6): 1079-1089.

53. Williams RL, Hilton DJ, Pease S, et al. Myeloid leukaemia inhibitory factor maintains the developmental potential of embryonic stem cells. Nature. 1988;336(6200):684-687.

54. Niwa H, Miyazaki J, Smith AG. Quantitative expression of Oct-3/4 defines differentiation, dedifferentiation or self-renewal of ES cells. Nat Genet. 2000;24(4):372-376.

55. Amsterdam A, Raanan C, Schreiber L, Freyhan O, Schechtman L, Givol D. Localization of the stem cell markers LGR5 and Nanog in the normal and the cancerous human ovary and their inter-relationship. Acta Histochem. 2013;115(4):330-338.

56. Ezeh UI, Turek PJ, Reijo RA, Clark AT. Human embryonic stem cell genes OCT4, NANOG, STELLAR, and GDF3 are expressed in both seminoma and breast carcinoma. Cancer. 2005;104(10):2255-2265.

57. Hart AH, Hartley L, Parker K, et al. The pluripotency homeobox gene NANOG is expressed in human germ cell tumors. Cancer. 2005;104(10):2092-2098.

58. Hoei-Hansen CE, Almstrup K, Nielsen JE, et al. Stem cell pluripotency factor NANOG is expressed in human fetal gonocytes, testicular carcinoma in situ and germ cell tumours. Histopathology. 2005;47(1):48-56.

59. Lin T, Ding YQ, Li JM. Overexpression of Nanog protein is associated with poor prognosis in gastric adenocarcinoma. Med Oncol. 2012;29(2): $878-885$.
60. Guo Y, Liu S, Wang P, et al. Expression profile of embryonic stem cell-associated genes Oct4, Sox2 and Nanog in human gliomas. Histopathology. 2011;59(4):763-775.

61. Pan Y, Jiao J, Zhou C, Cheng Q, Hu Y, Chen H. Nanog is highly expressed in ovarian serous cystadenocarcinoma and correlated with clinical stage and pathological grade. Pathobiology. 2010;77(6): 283-288.

62. Wen J, Park JY, Park KH, et al. Oct4 and Nanog expression is associated with early stages of pancreatic carcinogenesis. Pancreas. 2010;39(5): 622-626.

63. Chiou SH, Yu CC, Huang CY, et al. Positive correlations of Oct-4 and Nanog in oral cancer stem-like cells and high-grade oral squamous cell carcinoma. Clin Cancer Res. 2008;14(13):4085-4095.

64. Gillis AJ, Stoop H, Biermann K, et al. Expression and interdependencies of pluripotency factors LIN28, OCT3/4, NANOG and SOX2 in human testicular germ cells and tumours of the testis. Int $J$ Androl. 2011;34(4 Pt 2):e160-e174.

65. Zhou X, Zhou YP, Huang GR, et al. Expression of the stem cell marker, Nanog, in human endometrial adenocarcinoma. Int J Gynecol Pathol. 2011;30(3):262-270.

66. Nagata T, Shimada Y, Sekine S, et al. Prognostic significance of NANOG and KLF4 for breast cancer. Breast cancer. 2012.

67. Lee M, Nam EJ, Kim SW, Kim S, Kim JH, Kim YT. Prognostic impact of the cancer stem cell-related marker NANOG in ovarian serous carcinoma. Int J Gynecol Cancer. 2012;22(9):1489-1496.

68. Meng HM, Zheng P, Wang XY, et al. Overexpression of nanog predicts tumor progression and poor prognosis in colorectal cancer. Cancer Biol Ther. 2010;9(4).

69. Niu CS, Li DX, Liu YH, Fu XM, Tang SF, Li J. Expression of NANOG in human gliomas and its relationship with undifferentiated glioma cells. Oncol Rep. 2011;26(3):593-601.

70. Jeter CR, Liu B, Liu X, et al. NANOG promotes cancer stem cell characteristics and prostate cancer resistance to androgen deprivation. Oncogene. 2011;30(36):3833-3845.

71. Po A, Ferretti E, Miele E, et al. Hedgehog controls neural stem cells through p53-independent regulation of Nanog. EMBO J. 2010;29(15): 2646-2658.

72. Villasante A, Piazzolla D, Li H, Gomez-Lopez G, Djabali M, Serrano M. Epigenetic regulation of Nanog expression by Ezh2 in pluripotent stem cells. Cell Cycle. 2011;10(9):1488-1498.

73. Xu F, Dai C, Zhang R, Zhao Y, Peng S, Jia C. Nanog: a potential biomarker for liver metastasis of colorectal cancer. Dig Dis Sci. 2012; 57(9):2340-2346.

74. He A, Qi W, Huang Y, et al. CD133 expression predicts lung metastasis and poor prognosis in osteosarcoma patients: A clinical and experimental study. Exp Ther Med. 2012;4(3):435-441.

75. Leung EL, Fiscus RR, Tung JW, et al. Non-small cell lung cancer cells expressing CD44 are enriched for stem cell-like properties. PLoS One. 2010;5(11):e14062.

76. Han J, Zhang F, Yu M, et al. RNA interference-mediated silencing of NANOG reduces cell proliferation and induces $\mathrm{G} 0 / \mathrm{G} 1$ cell cycle arrest in breast cancer cells. Cancer Lett. 2012;321(1):80-88.

77. Choi SC, Choi JH, Park CY, Ahn CM, Hong SJ, Lim DS. Nanog regulates molecules involved in stemness and cell cycle-signaling pathway for maintenance of pluripotency of $\mathrm{P} 19$ embryonal carcinoma stem cells. J Cell Physiol. 2012;227(11):3678-3692.

78. Siu MK, Wong ES, Kong DS, et al. Stem cell transcription factor NANOG controls cell migration and invasion via dysregulation of E-cadherin and FoxJ1 and contributes to adverse clinical outcome in ovarian cancers. Oncogene. 2013;32(30):3500-3509.

79. Noh KH, Kim BW, Song KH, et al. Nanog signaling in cancer promotes stem-like phenotype and immune evasion. J Clin Invest. 2012;122(11):4077-4093

80. Noh KH, Lee YH, Jeon JH, et al. Cancer vaccination drives Nanog-dependent evolution of tumor cells toward an immuneresistant and stem-like phenotype. Cancer Res. 2012;72(7): $1717-1727$. 
81. Gu TT, Liu SY, Zheng PS. Cytoplasmic NANOG-positive stromal cells promote human cervical cancer progression. Am J Pathol. 2012;181(2):652-661.

82. Kalmar T, Lim C, Hayward P, et al. Regulated fluctuations in nanog expression mediate cell fate decisions in embryonic stem cells. PLoS Biol. 2009;7(7):e1000149.

83. MacArthur BD, Sevilla A, Lenz M, et al. Nanog-dependent feedback loops regulate murine embryonic stem cell heterogeneity. Nat Cell Biol. 2012;14(11):1139-1147.

84. Golubovskaya VM. FAK and Nanog cross talk with p53 in cancer stem cells. Anticancer Agents Med Chem. 2013;13(4):576-580.

85. Lin T, Chao C, Saito S, et al. p53 induces differentiation of mouse embryonic stem cells by suppressing Nanog expression. Nat Cell Biol. 2005;7(2):165-171.

86. Moon JH, Kwon S, Jun EK, et al. Nanog-induced dedifferentiation of p53-deficient mouse astrocytes into brain cancer stem-like cells. Biochem Biophys Res Commun. 2011;412(1):175-181.

87. Hong H, Takahashi K, Ichisaka T, et al. Suppression of induced pluripotent stem cell generation by the p53-p21 pathway. Nature. 2009;460(7259):1132-1135.

88. Yu J, Vodyanik MA, Smuga-Otto K, et al. Induced pluripotent stem cell lines derived from human somatic cells. Science. 2007;318(5858): 1917-1920.

89. Clement V, Sanchez P, de Tribolet N, Radovanovic I, Ruiz i Altaba A. HEDGEHOG-GLI1 signaling regulates human glioma growth, cancer stem cell self-renewal, and tumorigenicity. Curr Biol. 2007;17(2):165-172.

90. Bourillot PY, Aksoy I, Schreiber V, et al. Novel STAT3 target genes exert distinct roles in the inhibition of mesoderm and endoderm differentiation in cooperation with Nanog. Stem Cells. 2009;27(8): 1760-1771.

91. Torres J, Watt FM. Nanog maintains pluripotency of mouse embryonic stem cells by inhibiting NFkappaB and cooperating with Stat3. Nat Cell Biol. 2008;10(2):194-201.

92. Bourguignon LY, Earle C, Wong G, Spevak CC, Krueger K. Stem cell marker (Nanog) and Stat-3 signaling promote MicroRNA-21 expression and chemoresistance in hyaluronan/CD44-activated head and neck squamous cell carcinoma cells. Oncogene. 2012;31(2):149-160.

93. Suzuki A, Raya A, Kawakami Y, et al. Nanog binds to Smad1 and blocks bone morphogenetic protein-induced differentiation of embryonic stem cells. Proc Natl Acad Sci U S A. 2006;103(27):10294-10299.

94. Tang Y, Luo Y, Jiang Z, et al. Jak/Stat3 signaling promotes somatic cell reprogramming by epigenetic regulation. Stem Cells. 2012;30(12): 2645-2656.

95. Hawkins K, Mohamet L, Ritson S, Merry CL, Ward CM. E-cadherin and, in its absence, $\mathrm{N}$-cadherin promotes Nanog expression in mouse embryonic stem cells via STAT3 phosphorylation. Stem Cells. 2012;30(9):1842-1851.

96. Tay Y, Zhang J, Thomson AM, Lim B, Rigoutsos I. MicroRNAs to Nanog, Oct 4 and Sox 2 coding regions modulate embryonic stem cell differentiation. Nature. 2008;455(7216):1124-1128.

97. Tay YM, Tam WL, Ang YS, et al. MicroRNA-134 modulates the differentiation of mouse embryonic stem cells, where it causes post-transcriptional attenuation of Nanog and LRH1. Stem Cells. 2008;26(1):17-29.

98. Niu CS, Yang Y, Cheng CD. MiR-134 regulates the proliferation and invasion of glioblastoma cells by reducing Nanog expression. Int $J$ Oncol. 2013;42(5):1533-1540.

99. Penna E, Orso F, Cimino D, et al. microRNA-214 contributes to melanoma tumour progression through suppression of TFAP2C. EMBO J. 2011;30(10):1990-2007.

100. Yang H, Kong W, He L, et al. MicroRNA expression profiling in human ovarian cancer: miR-214 induces cell survival and cisplatin resistance by targeting PTEN. Cancer Res. 2008;68(2):425-433.

101. Xu CX, Xu M, Tan L, et al. MicroRNA miR-214 regulates ovarian cancer cell stemness by targeting p53/Nanog. J Biol Chem. 2012;287(42): 34970-34978.
102. Fareh M, Turchi L, Virolle V, et al. The miR 302-367 cluster drastically affects self-renewal and infiltration properties of glioma-initiating cells through CXCR4 repression and consequent disruption of the $\mathrm{SHH}$ GLI-NANOG network. Cell Death Differ. 2012;19(2):232-244.

103. Piestun D, Kochupurakkal BS, Jacob-Hirsch J, et al. Nanog transforms NIH3T3 cells and targets cell-type restricted genes. Biochem Biophys Res Commun. 2006;343(1):279-285.

104. Lin YL, Han ZB, Xiong FY, et al. Malignant transformation of 293 cells induced by ectopic expression of human Nanog. Mol Cell Biochem. 2011;351(1-2):109-116.

105. Park SW, Lim HY, Do HJ, et al. Regulation of human growth and differentiation factor 3 gene expression by NANOG in human embryonic carcinoma NCCIT cells. FEBS Lett. 2012;586(19):3529-3535.

106. Yin X, Li YW, Zhang BH, et al. Coexpression of stemness factors Oct4 and Nanog predict liver resection. Ann Surg Oncol. 2012;19(9): 2877-2887.

107. Yang L, Zhang X, Zhang M, et al. Increased nanog expression promotes tumor development and Cisplatin resistance in human esophageal cancer cells. Cell Physiol Biochem. 2012;30(4):943-952.

108. Tsai LL, Yu CC, Chang YC, Yu CH, Chou MY. Markedly increased Oct4 and Nanog expression correlates with cisplatin resistance in oral squamous cell carcinoma. J Oral Pathol Med. 2011;40(8):621-628.

109. Bourguignon LY, Peyrollier K, Xia W, Gilad E. HyaluronanCD44 interaction activates stem cell marker Nanog, Stat-3-mediated MDR1 gene expression, and ankyrin-regulated multidrug efflux in breast and ovarian tumor cells. J Biol Chem. 2008;283(25):17635-17651.

110. Xu Y. A new role for $\mathrm{p} 53$ in maintaining genetic stability in embryonic stem cells. Cell Cycle. 2005;4(3):363-364.

111. van den Berg DL, Zhang W, Yates A, et al. Estrogen-related receptor beta interacts with Oct4 to positively regulate Nanog gene expression. Mol Cell Biol. 2008;28(19):5986-5995.

112. Festuccia N, Osorno R, Halbritter F, et al. Esrrb is a direct Nanog target gene that can substitute for Nanog function in pluripotent cells. Cell Stem Cell. 2012;11(4):477-490.

113. Abhold EL, Kiang A, Rahimy E, et al. EGFR kinase promotes acquisition of stem cell-like properties: a potential therapeutic target in head and neck squamous cell carcinoma stem cells. PLoS One. 2012;7(2):e32459.

114. Yang J, Liao D, Chen C, et al. Tumor-associated macrophages regulate murine breast cancer stem cells through a novel paracrine EGFR/Stat3/ Sox-2 signaling pathway. Stem Cells. 2013;31(2):248-258.

115. Yi D, Kuo SZ, Zheng H, et al. Activation of PDGFR and EGFR promotes the acquisition of a stem cell-like phenotype in schwannomas. Otol Neurot. 2012;33(9):1640-1647.

116. Ma L, Zhang G, Miao XB, et al. Cancer stem-like cell properties are regulated by EGFR/AKT/beta-catenin signaling and preferentially inhibited by gefitinib in nasopharyngeal carcinoma. FEBS J. 2013;280(9):2027-2041

117. Hyder A, Ehnert S, Hinz H, Nussler AK, Fandrich F, Ungefroren H. $\mathrm{EGF}$ and HB-EGF enhance the proliferation of programmable cells of monocytic origin (PCMO) through activation of MEK/ERK signaling and improve differentiation of PCMO-derived hepatocyte-like cells. Cell Commun Signal. 2012;10(1):23.

118. Watanabe S, Umehara H, Murayama K, Okabe M, Kimura T, Nakano T. Activation of Akt signaling is sufficient to maintain pluripotency in mouse and primate embryonic stem cells. Oncogene. 2006;25(19):2697-2707.

119. Storm MP, Bone HK, Beck CG, et al. Regulation of Nanog expression by phosphoinositide 3-kinase-dependent signaling in murine embryonic stem cells. J Biol Chem. 2007;282(9):6265-6273.

120. Xu C, Xie D, Yu SC, et al. beta-Catenin/POU5F1/SOX2 transcription factor complex mediates IGF-I receptor signaling and predicts poor prognosis in lung adenocarcinoma. Cancer Res. 2013;73(10): 3181-3189.

121. Lindgren AG, Natsuhara K, Tian E, et al. Loss of Pten causes tumor initiation following differentiation of murine pluripotent stem cells due to failed repression of Nanog. PLoS One. 2011;6(1):e16478. 
122. Ho B, Olson G, Figel S, Gelman I, Cance WG, Golubovskaya VM. Nanog increases focal adhesion kinase (FAK) promoter activity and expression and directly binds to FAK protein to be phosphorylated. J Biol Chem. 2012;287(22):18656-18673.

123. Wang ML, Pan CM, Chiou SH, et al. Oncostatin m modulates the mesenchymal-epithelial transition of lung adenocarcinoma cells by a mesenchymal stem cell-mediated paracrine effect. Cancer Res. 2012;72(22):6051-6064.

124. Zhu Y, Sun Z, Han Q, et al. Human mesenchymal stem cells inhibit cancer cell proliferation by secreting DKK-1. Leukemia. 2009;23(5): 925-933.

125. Orimo A, Gupta PB, Sgroi DC, et al. Stromal fibroblasts present in invasive human breast carcinomas promote tumor growth and angiogenesis through elevated SDF-1/CXCL12 secretion. Cell. 2005;121(3): 335-348.

126. Sun Z, Han Q, Zhu Y, et al. NANOG has a role in mesenchymal stem cells' immunomodulatory effect. Stem Cells Dev. 2011;20(9): 1521-1528.

127. Du Y, Shi L, Wang T, Liu Z, Wang Z. Nanog siRNA plus Cisplatin may enhance the sensitivity of chemotherapy in esophageal cancer. J Cancer Res Clin Oncol. 2012;138(10):1759-1767.

128. Shao W, Paul A, Abbasi S, et al. A novel polyethyleneimine-coated adeno-associated virus-like particle formulation for efficient siRNA delivery in breast cancer therapy: preparation and in vitro analysis. Int J Nanomedicine. 2012;7:1575-1586.

129. Chiou GY, Cherng JY, Hsu HS, et al. Cationic polyurethanes-short branch PEI-mediated delivery of Mir145 inhibited epithelialmesenchymal transdifferentiation and cancer stem-like properties and in lung adenocarcinoma. J Control Release. 2012;159(2):240-250.
130. Peng CH, Cherng JY, Chiou GY, et al. Delivery of Oct4 and SirT1 with cationic polyurethanes-short branch PEI to aged retinal pigment epithelium. Biomaterials. 2011;32(34):9077-9088.

131. Lo WL, Chien Y, Chiou GY, et al. Nuclear localization signalenhanced RNA interference of EZH2 and Oct4 in the eradication of head and neck squamous cell carcinoma-derived cancer stem cells. Biomaterials. 2012;33(14):3693-3709.

132. Machida $\mathrm{K}$, Tsukamoto $\mathrm{H}$, Mkrtchyan $\mathrm{H}$, et al. Toll-like receptor 4 mediates synergism between alcohol and HCV in hepatic oncogenesis involving stem cell marker Nanog. Proc Natl Acad Sci U S A. 2009;106(5):1548-1553.

133. Heddleston JM, Li Z, McLendon RE, Hjelmeland AB, Rich JN. The hypoxic microenvironment maintains glioblastoma stem cells and promotes reprogramming towards a cancer stem cell phenotype. Cell Cycle. 2009;8(20):3274-3284.

134. Kim JS, Kim BS, Kim J, Park CS, Chung IY. The phosphoinositide-3kinase/Akt pathway mediates the transient increase in Nanog expression during differentiation of F9 cells. Arch Pharm Res. 2010;33(7): 1117-1125.

135. Tsai CC, Su PF, Huang YF, Yew TL, Hung SC. Oct4 and Nanog directly regulate Dnmt1 to maintain self-renewal and undifferentiated state in mesenchymal stem cells. Mol Cell. 2012;47(2):169-182.
OncoTargets and Therapy

\section{Publish your work in this journal}

OncoTargets and Therapy is an international, peer-reviewed, open access journal focusing on the pathological basis of all cancers, potential targets for therapy and treatment protocols employed to improve the management of cancer patients. The journal also focuses on the impact of management programs and new therapeutic agents and protocols on

\section{Dovepress}

patient perspectives such as quality of life, adherence and satisfaction The manuscript management system is completely online and includes a very quick and fair peer-review system, which is all easy to use. Visit http://www.dovepress.com/testimonials.php to read real quotes from published authors. 